[Aikin, S. (2002). Can My Students Foot it With The Best? The Impact of Global Influences on the Primary Curriculum. New Zealand Annual Review of Education, 11, 145-160]

\section{Can My Students Foot it With The Best? The Impact of Global Influences on the Primary Curriculum}

\section{SANDRA AIKIN}

\section{Abstract:}

This article contributes to an emerging stream of ideas related to the globalised effects of the economy on education policy and practice. An attempt is made to assess the impact of global pressures on selected aspects of primary curriculum and assessment policies and practices, both in broad overview and in more detail. $^{1}$

uccessive New Zealand governments over the last 17 years have sought to liberalise the economy by the promotion of a free market enterprise and the application of financial rationalisation to all decisions, in order to gain a competitive advantage internationally. The direct and crucial relationship between New Zealand's economy and its education system has heralded great changes in school structures and processes. These trends are similar to what has been occurring in many OECD member countries.

In this article I contend that global pressures associated with the economy, including the ideology of a free market, have impacted significantly on primary school programmes. When political rhetoric causes contradictions and tensions, teachers either resist or assimilate within their professional knowledge, experience and commitment the expectations of government. The result is a softening of the intended impact of the global pressure as it is jostled to fit within teachers' education philosophy and practice.

To begin it is necessary to explore the complexity of the concept of globalisation within its economic frame, and establish the links between a set of related concepts such as "an enterprise culture", "international competitiveness" and "human capital" theory. This discussion provides the policy context within which teachers work and think about what they do. It also provides a framework to consider how teachers attempt to resolve tensions between the legitimate will of an elected government and their own professional judgement and commitment to student learning.

\section{Globalisation}

The term globalisation suggests a worldwide process. It refers to: the accelerated international flows of goods, capital, labour, services and information which have occurred in response to improved transport, the seemingly limitless revolution in communications technologies, and the deregulatory policies adopted in many countries during the past two decades. (Green, 1999, p. 57)

Green provides a useful analysis, highlighting the common contextual factors that are shaping policy making. He argues that the process of globalisation has greatly intensified economic competition, particularly between the advanced countries, that now "race to create the conditions which attract foreign investment by improving productivity and market competitiveness in home-based industries and services" (p. 57).

He argues that governments of advanced European economies are not able to compete with the low wage, low cost economies around the world. Those that wish to remain prosperous have little choice but to move further into the knowledge-intensive, high value-added areas of production and services to remain competitive with other economies. The shift implies an even greater emphasis on information-rich, high quality production and services where the premium is on rapid change and innovation (p. 57)

Using Green's analysis, it is easy to recognise New Zealand's response, which has led to significant changes in the organisation of its economy. Being innovative, entrepreneurial and competing by adding value is seen as the way to obtain the greatest economic rewards.

Changes in work organisation and the terms of international competition have presented education systems with new challenges.

In the first place, the need to reduce social costs to encourage competitiveness and to attract foreign investment has led to tight budgetary controls which have forced expanding education systems to be more cost efficient. In the second place, there has been a generalised demand for higher levels of qualification and skill 
throughout the workforce. At one level this has meant education and training systems focusing on promoting the social and personal skills which allow young people entering work to be flexible and adaptable and quick to learn in rapidly changing work environments. At another level, it has meant promoting more widely a range of skills that are seen to be of singular importance in modern working environments - the ability to communicate well, handle information, work in teams, solve new problems, apply knowledge and skills in different contexts and to think conceptually and creatively. (p. 58)

Dale (2002) provides a timely warning against viewing globalisation as a seamless and continuous process. ${ }^{2}$ He argues that there have been changes, and that globalisation cannot be reduced to a single set of imperatives. Nevertheless, he considers that those on the receiving end may well perceive it as having homogeneous elements.

While globalisation has had a powerful effect on economies, Mortimore (2001) poses the question of whether it can be as powerful in education. Certainly the reform of the economy by New Zealand's Labour Government (1984-1990), loosely termed as "Rogernomics" after its Minister of Finance, Roger Douglas, was analogous with today's concept of globalisation. The Labour Government created an environment suitable for economic reform, which became the mechanism to drive policy changes to educational administration. But it was the National-led Governments (1990-1999) that took up the challenge of aligning the school structures and processes to that of the economy. ${ }^{3}$

\section{The Local Twist}

The New Zealand National Government came to office (1990) with a clear policy to enhance educational achievement and skill development to meet the needs of a highly competitive, modern international economy. The need to be "competitive" was a favourite theme of the then Minister of Education, Lockwood Smith. Together with an emphasis on the subjects of science and technology, it was one of the main planks of National's education policy.

Fears about the decline of the economy, high youth unemployment, and "provider" capture led to arguments for change. Cooper \& Aikin (2001) identify some of the arguments as being the need to:

- modernise the curriculum and make it relevant to the needs of the economy (i.e., technology, ICT literacy)
- allow greater consumer choice (i.e., by parents, the community, business community)

- improve teaching quality and raise standards through assessment regimes

- reassert the "national" culture, language and identity

- reshape values (i.e., values inclusive of enterprise cultures and innovation)

- reassert the primacy of literacy and numeracy within the curriculum

Both the Labour and National governments in New Zealand have used these arguments to bring about a variety of policy changes in the education system. Major shifts have included: a move to selfmanagement of schools, the development of competition between schools for student enrolment, public recognition through marketing and advertising, changes in curriculum, and an increased requirement for schools to report on student achievement.

Tensions have been created as some of the changes conflict in their intent. For example, schools are encouraged to work collaboratively and are geographically clustered to participate in professional development and share resources. Yet the "marketing" of the school and enrolment legislation encourages schools to compete for the same students.

With these and a range of other changes to the educational environment came a demand for increased accountability. Schools needed to provide evidence of meeting the education standards and "ensure that more young people reach higher levels of knowledge and skill in the fierce international competition for economic success" (Hargreaves, 1999, p. 45). Teachers' roles were redefined as they moved into a more managerial and market driven environment which was now "layered on top of more traditional notions of professional and democratic accountability" (Vidovic \& Slee, 2001, p. 431).

\section{Not Teachers But Human Capital ${ }^{4}$}

Another means of developing a more competitive economy capable of competing in the global arena has been an open embrace of human capital theory (Kennedy, 1999, p. 23). This has resulted in a call for more rigorous monitoring of teacher performance including: teacher pay and performance linked to an arbitrary set of professional standards; the development of staff appraisal systems on all worksites; and the 
imposition of wider ranges of penalties for poorly performing teachers in cases of complaints or discipline. In New Zealand the latter has been legislated for through the creation of a Teachers Council.

Although not new, human capital theory has become a dominant influence in the economic debate alongside a call for "high standards" and "excellence". These concerns can be related to the need to ensure high levels of achievement in areas that are crucial to economic development and to disaffection with the schooling process, especially where educational innovation appears to sidetrack schools away from traditional academic programmes.

\section{A Culture of Enterprise}

The notion of enterprise culture is one that has been imported into the local context from Thatcher's Conservative Government in Britain. There, questions of national economic survival and competition in the world economy were seen as requiring a cultural change of values from community to individualism. In New Zealand, the Minister of Education, Lockwood Smith, used the notion of an enterprise culture as his vision for all education activity, whether it be through school organisation or curriculum.

At the heart of the notion of an "enterprise culture" is the importance of reconstructing education so that it will deliver the skills and attitudes required for New Zealand to compete in an increasingly competitive international economy .... we must invest heavily in education as the basis for future economic growth by redesigning the system so that it meets the needs of business and industry. (Smith, 1991)

Peters and Marshall (1996) trace the attempts to foster an enterprise culture in New Zealand to a number of strategic political events since 1990. These strategies, they argue, were modelled on British initiatives, and include the New Zealand Prime Minister's "Education for Enterprise" Conference (1992) held to forge links between the education and commercial sectors. More recently, the "Catching the Knowledge Wave Conference" in August 2001 reinforced the political and businessinitiated agenda that schools must focus on mathematics, science, technology and foster innovation if New Zealand is to have a sound economic infrastructure (Cooper \& Aikin, 2001).

An example of how primary schools had an opportunity to respond to the Minister's vision through the organisation of their learning programmes can be seen by a brief examination of the Primary Enterprise Programme (PrEP). Currently 165 primary schools have elected to participate in the PrEP sponsored by the Enterprise New Zealand Trust. The Trust is best known for the Fletcher Challenge Young Enterprise scheme that involves secondary school students in setting up a company and running a business. In primary schools, the Trust has supported PrEP as a programme for school children aged between five and eleven who design and operate their own functioning society within school. Ron Clink, an American consultant, former teacher and director of Economics America in Washington state, set up the programme for the Trust. PrEP is designed to harness students' entrepreneurial characteristics in a useful, cooperative structure described as "market-based within a democratic society".

The PrEP literature says:

students form their own government, have marketplaces for goods and services, hold jobs, spend, save and invest school currency and form student-run ventures in such professions as business, performing arts, publishing, services, manufacturing, fine arts, civic service, broadcasting and other. (O'Brien, 1998)

Organisation of learning on a specific theme for a school day or week or even a term is not new to New Zealand primary schools. What is different is a specific focus on the marketplace - goods and services and the emphasis on a school currency. The targeting of primary schools and their direct involvement in PrEP provides explicit evidence of the gradual influence of the enterprise culture on primary school teaching and learning programmes. Whereas the number of schools participating in PrEP is relatively small, it is these schools which are used as examples of good practice and what other schools should do. Other schools may have sound practices, but the lack of recognition or value placed on what they are doing and achieving creates a public perception that they are not up with the play.

To prepare New Zealanders for the new culture of enterprise and international competitive advantage, a key component of the National Government's strategy was founded on the perception of a "gap" between performance and potential. The school curriculum came under intense scrutiny.

\section{The New Zealand Curriculum Framework}

The New Zealand Curriculum Framework is an overarching statement which sets out the government of the day's economic, political and 
social agenda through its policy direction for curriculum and assessment programmes in schools. ${ }^{5}$ Explicitly stated is the desire for New Zealand to have a competitive edge in the international marketplace.

In the foreword to the framework, the then Secretary of Education, Maris O'Rourke stated:

Today, New Zealand faces many significant challenges. If we wish to progress as a nation, and to enjoy a healthy prosperity in today's and tomorrow's competitive world economy, our education system must adapt to meet these challenges. We need a learning environment which enables all our students to attain high standards and develop appropriate personal qualities ... we need a workforce which is highly skilled and adaptable and which has an international and multicultural perspective. (Ministry of Education, 1993, p. 1)

The framework sets out the foundation policy for teaching, learning and assessment in New Zealand schools. To this end it states principles, specifies seven essential learning areas, sets out essential skills, and indicates the place of attitudes and values in the school curriculum. The supporting national curriculum statements provide details for teachers' guidance on the required knowledge, understandings, skills and attitudes in each essential learning area. The curriculum is organised into levels with achievement aims and learning objectives which are to be reported against as a mapped progress report for any child.

The essential skills promoted on the frameworkinclude vocationally based ones to prepare an individual student to become an effective New Zealand citizen within the economic structures in society. Workforce knowledge and skills are stressed within a response to rapid technological change.

Some tensions in what is seen as desirable skills are obvious. Teachers are accountable for encouraging both cooperative teamwork in problem solving situations as well as teaching self-management and competitive skills! The framework lists these two groups of skills as if they were complementary and compatible and cause no dilemma for teachers (Ministry of Education, 1993, p. 19).

Desirable attitudes and values as stated within the framework are expected to underpin the culture of any school. O'Neill et al. (1998) see the guidance provided by the curriculum as an endorsement of the ethics and values of business, with the key features being personal and global competitiveness and consumerism. These values and those embedded in school and class practice are the messages which surround students.
At the local level, however, values are negotiated, stated explicitly and documented within school charters. Statements are operationalised through school policies on behaviour, codes of dress and agreed standards for work completion. Together these form a broad ranging set of quality standards to which the school and its community commit. They are the social and cultural glue of the school which underpin curriculum implementation. It is the democratic process of negotiation at the school level that filters political messages and safeguards the values the school's community wishes to endorse. ${ }^{6}$

The introduction of technology as a separate essential learning area led O'Neill and Jolley to argue that

Curriculum aims are specifically linked to the creation of a culture based on a commercial conception of enterprise. Production, packaging and marketing are emphasised. This immediately locates children as learners in the realm of the market-place as opposed to learners/cooks in the context of the home. (1996, p. 234)

Teachers have been influenced by the introduction of the new curriculum statement for technology, by the rapid introduction of electronic technology and its ability to open up new experiences that were previously beyond the capability of the primary classroom. With the new technologies have come a need to refine and re focus teaching programmes and methodologies that support problem based learning (Cooper \& Aikin, 2001).

In implementing the curriculum, emphasis is placed on using authentic contexts and problems. Included are problem solving skills, such as "thinking critically, redefining and analysing a problem, making connections, researching, designing and making, testing ideas and solutions, evaluating" (Ministry of Education, 1993, p. 19).

Primary teachers welcome this emphasis because it reflects how good teaching already occurs in practice.

Curriculum aspects are fully integrated in pursuit of a meaningful investigation .... Each project uses complex thinking skills and teachers not only scaffold process and procedural skills but also develop and structure the thinking needed as part of the problem solving strategy. (Cooper \& Aikin, 2001, p. 9)

The measurement of results by narrow paper and pencil testing is not an appropriate technique for the emerging teaching models such as those described. Yet the need for comparative information on achievement is an essential indicator in a competitive global 
environment. Participation in international surveys of achievement has become of increasing importance.

\section{Feel Our Pulse}

Elley (1999) comments that international surveys of achievement are becoming regular events, and valuable sources of policy information in many countries. In particular, primary schools have become accustomed to the Third International Mathematics Study (TIMSS), a four-year cycle of studies in mathematics and science beginning in 1995; and the Progress in International Reading Literacy Study (PIRLS), designed to provide comparative information on reading literacy, beginning in 2001 and also conducted every four years, but on a different schedule from TIMSS.

A new OECD initiative is its Programme for International Student Assessment (PISA). The aim of the project is to collect data on student knowledge, skills and competencies in reading, mathematics and science from 32 member countries. The data collection began in 2000 and future surveys are planned for 2003, 2006 and 2009. The size and scope of PISA is ambitious, and unlike other similar projects, PISA defines its own goals to define domains, rather than accept the national curriculum of participating countries. The results from the first round of PISA, as well as its approach, are yet to be judged. However, the influential role the OECD plays in the provision of advice and the endorsement of economies suggests that the PISA proficiency levels will have a great impact on national education policies.

It is true that an appreciation of other countries' education systems and practices can help us better understand our own educational system. The economic success of countries such as Japan, South Korea and Singapore is attributed partly to the characteristics of their schools and curriculum. Their success places them in the spotlight as educational role models. But comparing international test results does not provide a basis to judge which education systems are the most successful (Winter, 1998).

New Zealand media headlines, however, report the results in high profile "league tables" as if these were the Education Olympics. The emphasis is on New Zealand's failure to reach the dais of the top three medal winners rather than any acknowledgement of areas of success.
Morris maintains that:

The whole use of comparisons across educational systems, designed to generate "quick fix" policies, is largely premised on a simplified notion about the relationship between schooling and economic growth which infers that increased output is a function of increased productivity. (1998, p. 6)

International comparisons, such as those produced by the International Association for the Evaluation of Educational Achievement (IEA) studies, invariably produce accountability policies in the national context.

In May 1998, the New Zealand National Government released its Green Paper Assessment for Success in Primary Schools. In September 1999 its policy decisions were announced. The Government proposed development of a package of assessment tools to gather information and support learning. Tools already in use, such as the Assessment Resource Banks and the National Education Monitoring Project, were to be enhanced. Exemplars in selected learning areas were to be introduced. Also to be developed and trialled were externallyreferenced literacy and numeracy tests (asTTle). It was intended that these tests would become mandatory for all students at year 5 and year 7 .

Ministry information emphasised the connections between clear goals, student motivation and improvement. Teachers, however, viewed the assessment tools provided under asTTle with suspicion, believing that their development was for accountability rather than educational purposes.

Outcomes-based education such as that outlined in the New Zealand Curriculum Framework demands that individuals are able to show what they have learned. The notion of individual achievement is a crucial one to the development of a child's learning. So assessment of student performance becomes the central issue. And reporting is inseparable from assessment. In a competitive environment, reporting is steered towards supporting an accountability system rather than supporting the professional judgement of teachers.

A change of political power brought a Labour Government to office, but this did not necessarily indicate a change of direction. The Labour Government introduced the Education Standards Act 2001, which continued to reinforce the ideology of a business model and business practices as being the most suitable for the operation of schools. The Act requires schools to have a strategic plan, to set targets for student achievement on an annual basis and to report on student performance. 
Reporting is done by providing an analysis of "any variance between the school's performance and the relevant aims, objectives, priorities or targets set out in the school charter" (Education Standards Act, Section 87(2)). The Act, together with key electronic strategic initiatives under the Management Information and Resourcing umbrella ultimately culminate in a school "warehouse of information". These initiatives depend on the successful transfer and exchange of data between schools and the Ministry.

This focus on data collection and exception reporting has the capacity to compromise teacher professionalism and learning programmes, and it is contrary to primary teaching pedagogy. Primary teachers aim to help students develop to their full potential. Having to state that so many students will be at a particular level at a particular time, and to publish and report this statistic externally, converts the purpose of assessment from formative to purely summative. It also creates the illusion that assessments can be a precise measure. If the reputation of the school or the teacher depends upon the accuracy of the target setting, then this may encourage teachers to be extremely cautious in voicing expectations.

Unfortunately politicians, bureaucrats and the media like simple comparative statistics. Testing often focuses on comparing the learning of cohorts of students on easily measured tests. Thus the international pressure to participate tends to place the focus onto learning areas such as science and mathematics or aspects of literacy, reading in particular. The scale of the measurement, too, affects the choice of assessment tool, which is generally constrained to be a "paper and pencil" test. This has limited appeal for teachers who are more concerned with the academic and social growth of their students. Other areas such as the creative, the aesthetic, the linguistic and problem-solving receive relatively little attention. As well, standard reporting may negate the unique nature of individual schools, and reporting using externally referenced tests, such as those promoted in asTTle, can easily turn into "high-stakes" national testing.

In a free market education environment, the scale and nature of the information collected in such tests can create undue pressures on students. Teachers, too, have remained sceptical about assurances from politicians that safeguards will be built in to prevent the abuse of assessment information in the problematic "league table" formats. They are well aware of the experiences of countries that have adopted compulsory national "paper and pencil" testing, and have used this information to ensure parents are aware of what is, and what is not, sound educational practice.

\section{Back to the Three Rs}

The increasing complexity of our society and the need for a flexible and highly educated workforce mean that individuals need to be able to understand and apply information of varying difficulty from a range of sources to function effectively at work and in everyday life. Literacy and numeracy skills are seen as the key to all areas of learning.

The focus on literacy and numeracy is often interpreted in a very narrow way as access to qualifications and employment. At the same time, teachers are exhorted to provide a broad and balanced curriculum, as the workplace of tomorrow requires flexible, motivated, creative workers who are able to work in and with a team of colleagues. Emphasis on the three Rs and a broad curriculum, however, are not incompatible with each other. The tension only arises when the assessment and reporting of literacy and numeracy achievement restricts the learning.

With the objective of raising overall achievement and closing the learning gap between the lowest and highest achievers, a theme identified through IEA studies, the National Government launched a literacy and numeracy strategy in which it set the target that "by 2005, every child aged nine will be able to read, write and do maths for success." ${ }^{7}$

Primary teachers found the initiative as laudable but surprising. Liz Patara, NZEI Te Riu Roa National President, in a media release responding to the announcement of the strategy, commented: "For primary schools, the initiative will mean little change. Teachers already emphasise reading, writing and maths, with other aspects of the curriculum involving less time" (NZEI, 1998, October). Education Minister Wyatt Creech responded that the initiative was aimed at children "at the bottom of the ladder".

An editorial in the New Zealand Herald (October 22, 1998) saw the strategy as an acknowledgement by the Minister that

Changing workforce requirements will place greater emphasis on the accumulation of skills. This is an era in which the advent of an information-driven society has meant that the skill of acquiring, organising and analysing information is as basic as reading, writing and adding. And it is certainly not possible to embrace the first without being proficient in the others. 
Inevitably, however, the media headlines in New Zealand questioned whether education "standards were slipping when it comes to children learning the three Rs." ${ }^{\prime 7}$

Hargreaves argues that these concerns about access to "the basics" have always been on the policy agenda, but now they are accompanied by some new themes, including

how what is learned in school, not just the content of the curriculum but also motivation and commitment to learning, prepares the young for lifelong learning and, as part of this, how skills in the use of the new information and communication technologies can be fostered in school. (1996, p. 45)

\section{Conclusion}

This article contends that global pressures associated with the economy have impacted on primary school programmes. Whether these pressures have made a difference to student achievement or whether any improvements to learning would have resulted without the reform to the curriculum along economic lines is more difficult to determine. Longitudinal surveys by Wylie (1997) found

Most primary teachers who felt the education reforms had improved the quality of education received by their students had also made changes to their curriculum, guided by the national curriculum changes. Very few teachers had had to abandon any initiatives originated in their own school.

What is apparent is that pressures for educational reform have merged with solutions used in the economic reforms. This has resulted in some conflicting policies. The teacher's role and exercise of professional judgement are squeezed between the two initiatives. But teachers are not passive recipients of education policy. Together with parents and the wider school community, they play a key role in ensuring democratic and civilizing ideals and values espoused through education maintain a place in teaching and learning programmes. All curriculum policy is mediated at the school and classroom level. "Spaces" that appear between the contradictions allow flexibility and opportunity for the exercise of professional discretion. In these "spaces" accommodation of contradictory forces can be accommodated and reshaped.

Notes

1. For a case study examination of the expectations of the New Zealand school curriculum and global pressures, see Cooper \& Aikin (2001).
2. Dale, R. (2002), private communication.

3. Between 1984 and 2002 was a period of tumult politically as well as educationally. New Zealand had six Ministers of Education during this time. Labour government ministers David Lange and Phil Goff were followed in turn by National government ministers: Lockwood Smith, Wyatt Creech, and Nick Smith. In 1999 Labour returned to power and Trevor Mallard became Minister of Education, a position which he currently holds.

4. In the economic literature the "human capital" theory sees education and training as part of an individual's investment that can be recouped in the form of higher lifetime earnings.

5. Interestingly, the framework itself has never been given the same legal status that the national curriculum statements enjoy.

6. Although the National Administrative Guidelines set an expectation that schools consult with their Maori communities and report on student achievement, the Education Amendment Bill No. 2, clause 8, removed the statutory requirement for every school to develop a charter in consultation with its community, staff and Maori.

7 For example, Otago Daily Times, October 26, 1998, "Education standards a concern"; New Zealand Herald, October 23, 1998, "Teaching fails expert 'then and now' test"; Marlborough Express, October 23, 1998," Teachers tell why our kids can't read."

\section{References}

Cooper, I. \& Aikin, S. (2001). What have I taught them today and does it fit with the world plan? Paper presented at Australian Curriculum Studies Association biennial national conference: Education Futures and New Citizenship, Canberra, Australia.

Dale, R. (1999). Specifying globalization effects on national policy: A focus on the mechanisms. Journal of Education Policy, 14(1), 1-18.

Elley, W. (1999, June 4). The untruth about adult literacy. New Zealand Education Review, 4(5), 7.

Gough, N. (1999). Globalisation and school curriculum change: Locating a transnational imaginary. Journal of Education Policy, 14(1), 73-84.

Green, A. (1999). Education and globalisation in Europe and East Asia: Convergent and divergent trends. Journal of Education Policy, 14(1), $55-72$. 
Hargreaves, D. (1999). Schools and the future: The key role of innovation. In Centre for Educational Research and Innovation, Innovating schools (pp. 45-56). Paris: OECD.

Kennedy, K. (1999). Constructing the school curriculum for the global society. In Centre for Educational Research and Innovation. Innovating schools (pp. 19-41). Paris: OECD.

Ministry of Education. (1993). The New Zealand Curriculum Framework. Wellington: Learning Media.

Ministry of Education. (1999). Information for Better Learning. National assessment in primary schools: Policies and proposals. Wellington: Ministry of Education.

Morris, P. (1998, June). Comparative education and educational reform: Beware of prophets returning from the Far East. Education 3 to 13, 26(2), 3-8.

Mortimore, P. (2001). Globalisation, effectiveness and improvement. School Effectiveness and School Improvement, 12(1), 229-249.

New Zealand Literacy Taskforce. (1999). Report of the Literacy Taskforce advice to Government on achieving its goal "That by 2005 every child turning nine will be able to read and write, and do maths for success." Prepared for the Minister of Education. Wellington: Ministry of Education.

O'Brien, P. (1998, August 14). Children learn to design and run their own society. The National Business Review, p. 30.

O’Neill, A., \& Jolley, S. (1996-97). Privatising curriculum: Constructing consumer society. The technology curriculum: The politics of food - women's work? To high tech or oblivion. In O'Neill, A. (Ed.), Curriculum reform: Development issue. Delta 48(2), 49(1), 221-249.

O’Neill, A., O’Neill, J., \& Clark, J. (1998, May 20). The politics of curriculum. New Zealand Education Review, p. 12.

Peters, M., \& Marshall, J. (1996). The politics of curriculum: Busnocratic rationality and enterprise culture. Delta 48(1), 3-46.

Smith, L. (1991). Education policy: Investing in people, our greatest asset. Wellington: Government Printer.

Vidovic, L., \& Slee, R. (2001). Bringing universities to account? Exploring some global and local policy tensions. Journal of Education Policy, 16(5), 431-453.
Winter, S. (1998. June). International comparisons of student achievement: Can they tell us which nations perform best and which education systems are the most successful? Education 3 to 13, 26(2), 26-32.

Wylie, C. (1997). Self-managing schools. Seven years on - what have we learnt? Wellington: New Zealand Council for Educational Research.

\section{Acknowledgements}

This work was completed with the encouragement and support of colleagues and friends. My thanks go to Ruth Mansell, Cathy Wylie, Roger Dale, Stephen Day, Helen Kelly and in particular Cathie Penetito.

\section{The author}

Sandra Aikin is currently employed as a Senior Officer at the New Zealand Educational Institute Te Riu Roa. Her work involves close liaison with practising primary school teachers in matters dealing with curriculum, assessment and other professional issues. 